CARDIOVASCULAR MEDICINE

\title{
Pulsed tissue Doppler imaging detects early myocardial dysfunction in asymptomatic patients with severe mitral regurgitation
}

\author{
E Agricola, M Galderisi, M Oppizzi, A F L Schinkel, F Maisano, M De Bonis, A Margonato, \\ A Maseri, O Alfieri
}

Heart 2004;90:406-410. doi: 10.1136/hrt.2002.009621

See end of article for authors' affiliations ......................

Correspondence to: DrE Agricola, Cardiologia Diagnostica Non-Invasiva, Ospedale San Raffaele, IRCCS, Via Olgettina 60 20132 Milan, Italy; agricola.eustachio@hsr.it

Accepted 31 July 2003

\begin{abstract}
Objective: To assess whether tissue Doppler myocardial imaging (TDI) indices can predict postoperative left ventricular function in patients with mitral regurgitation (MR) after surgical correction. Methods: 84 patients (mean (SD) age 54.3 (10.8) years) with asymptomatic severe MR, an end systolic diameter $<45 \mathrm{~mm}$, and an ejection fraction (EF) $>60 \%$ were subdivided in two groups: 43 patients with a postoperative $\mathrm{EF}$ reduction $<10 \%$ (group 1 ) and 41 patients with a postoperative $\mathrm{EF}$ reduction $\geqslant 10 \%$ (group 2).TDI systolic indices of the lateral annulus were analysed preoperatively to assess myocardial systolic wave $(\mathrm{Sm})$ velocity, myocardial precontraction time (PCTm), myocardial contraction time (CTm), and the PCTm:CTm ratio.

Results: Postoperative EF decreased significantly (from 67 (5)\% to 60 (5.5)\%, p = 0.0001). Group 2 had a higher PCTm, CTm, and PCTm:CTm ratio and a lower Sm velocity than group 1 (PCTm 100.4 (19) ms v 82 (21.8) ms, $p=0.004 ; C T m 222$ (3.1) ms v 215 (2.3) ms, $p=0.01 ;$ PCTm:CTm 0.45 (0.08) v 0.38 (0.09), $p=0.001 ; \mathrm{Sm}$ velocity $10.4(1.1) \mathrm{cm} / \mathrm{s} v 13(1.3) \mathrm{cm} / \mathrm{s}, \mathrm{p}=0.0001)$. Multivariate regression analysis showed that the combination of PCTm:CTm ratio $\geqslant 40 \mathrm{~ms}$ and $\mathrm{Sm}$ velocity $\leqslant 10.5 \mathrm{~cm} / \mathrm{s}$ was the main independent predictor of postoperative EF reduction $\geqslant 10 \%$ (sensitivity $78 \%$, specificity $95 \%$ ).

Conclusions: TDI systolic indices can predict postoperative left ventricular function in patients with asymptomatic MR undergoing surgical correction.
\end{abstract}

$\mathrm{P}$ reoperative left ventricular (LV) dysfunction is a risk factor for postoperative worsening of LV function and decreased long term survival in asymptomatic patients with severe mitral regurgitation (MR). ${ }^{1-4}$ Compared with patients who undergo surgery before the development of LV dysfunction, patients with LV impairment experience a greater fall in ejection fraction (EF) after surgery, an increased incidence of heart failure, and a higher mortality. ${ }^{12}$

Several parameters have been proposed for asymptomatic patients with chronic MR to assess LV function. EF is the most commonly used. ${ }^{1256}$ However, the assessment of EF depends on afterload and EF remains higher than normal during the compensated phase of chronic MR. When LV dysfunction develops, EF may fall but remains within normal limits because of a reduced afterload. Other more sensitive indices than EF have been proposed for detecting early myocardial dysfunction in chronic MR: end systolic volume corrected for body surface area and end systolic LV cavity dimension. ${ }^{4-11}$ However, despite serial preoperative testing with these parameters, postoperative LV dysfunction remains poorly predictable. LV cavity dimensions and EF are indirect measurements of the intrinsic myocardial function and both reflect the haemodynamic consequences of MR.

A mechanism of early myocardial dysfunction in patients with chronic volume overload may be alterations of subendocardial fibres. ${ }^{12}$ As the subendocardial fibres are aligned longitudinally, we hypothesised that LV long axis function would be preciously and noticeably altered in patients with asymptomatic severe MR. Mitral annular velocities reflect the contraction of longitudinal subendocardial fibres and can be measured by tissue Doppler myocardial imaging (TDI). ${ }^{13} 14$ Therefore, in this study we used the TDI systolic indices as potential echocardiographic indicators of subnormal LV performance, assessing the hypothesis that patients with asymptomatic severe MR and normal EF but with altered TDI systolic indices should develop significantly decreased postoperative LV function.

\section{PATIENTS AND METHODS \\ Study population}

Eighty four consecutive patients with asymptomatic (New York Heart Association functional class < II) severe isolated MR were studied (table 1). The inclusion criteria were LV end systolic diameter $<45 \mathrm{~mm}$, LV end systolic volume $<60 \mathrm{ml} /$ $\mathrm{m}^{2}$, and LVEF $>60 \%$. The causes of MR were myxomatous degeneration in 78 patients, rheumatic in 4 , and calcific in 2 elderly patients. According to the EF reduction after surgical correction, the study population was divided into two groups: group 1 with an EF reduction $\leqslant 10 \%$ and group 2 with an EF reduction $>10 \% .{ }^{6}{ }^{15}$ All patients underwent coronary angiography to rule out coronary artery disease. The exclusion criteria were coronary artery disease, aortic valvar disease, mitral stenosis, congenital heart disease, cardiomyopathy, diabetes mellitus, and arterial hypertension. All patients gave informed consent.

\section{Echocardiographic study}

All patients underwent preoperative and postoperative transthoracic echocardiography. The preoperative transthoracic

Abbreviations: Am, myocardial atrial contraction; $\mathrm{CTm}$, myocardial contraction time; $\mathrm{EF}$, ejection fraction; Em, myocardial early contraction; $\mathrm{LV}$, left ventricular; MR, mitral regurgitation; PCTm, myocardial precontraction time; Sm, myocardial systolic wave; TDI, tissue Doppler myocardial imaging 


\begin{tabular}{|c|c|}
\hline Feature & Mean (SD) or total \\
\hline Age (years) & $54.3(10.8)$ \\
\hline Sex (male/female) & $55 / 29$ \\
\hline $\mathrm{BSA}\left(\mathrm{m}^{2}\right)$ & $1.8(0.15)$ \\
\hline EDD $(\mathrm{mm})$ & $58.4(7.2)$ \\
\hline $\mathrm{ESD}(\mathrm{mm})$ & $35(7.2)$ \\
\hline $\operatorname{EDV}\left(\mathrm{ml} / \mathrm{m}^{2}\right)$ & 68 (19) \\
\hline $\mathrm{ESV}\left(\mathrm{ml} / \mathrm{m}^{2}\right)$ & $22.5(7.7)$ \\
\hline LVMI $\left(\mathrm{g} / \mathrm{m}^{2}\right)$ & $129.7(35.7)$ \\
\hline EF (\%) & $67.3(4.9)$ \\
\hline SPAP (mm Hg) & $31.4(9.4)$ \\
\hline
\end{tabular}

BSA, body surface area; EDD, end diastolic diameter; EDV, end diastolic volume; EF, ejection fraction; ESD, end systolic diameter; ESV, end systolic volume; LVMI, left ventricular mass index; SPAP, systolic pulmonary artery pressure.

examination was performed to assess the severity of MR and to measure LV internal diameters, indices of global LV function, and systolic pulmonary artery pressure.

The severity of MR was assessed semiquantitatively by colour Doppler flow imaging on a scale of 0 to $4+$ measuring the vena contracta width at the narrowest portion of the regurgitant jet. Vena contracta width was measured in each view from the systolic frame with the largest diameter of a clearly defined vena contracta. ${ }^{16}$ Moreover, we translated the degree of severity of MR into a $0-4+$ scale as follows: vena contracta width $\leqslant 0.3 \mathrm{~cm}, 1+;>0.3$ to $\leqslant 0.5 \mathrm{~cm}, 2+;>0.5$ to $\leqslant 0.8 \mathrm{~cm}, 3+$; and $>0.8 \mathrm{~cm}, 4+$.

$\mathrm{LV}$ volumes and EF were obtained by the biplane Simpson's method. LV mass was calculated according to the Penn convention and corrected for body surface area. ${ }^{17}$ Then, on the same day, all patients underwent transoesophageal echocardiography to study the characteristics of the MR. All echocardiographic examinations were done with the Sonos 5500 equipment (Agilent Technologies, Andover, Massachusetts, USA).

\section{Tissue Doppler imaging}

TDI was performed with transducer frequencies of 1.83.6 MHz with minimum optimal gain as possible to obtain the best signal to noise ratio. In the apical four chamber view, a $5 \mathrm{~mm}$ pulsed Doppler sample volume was placed at the level of the lateral mitral annulus. The incident angle between the interrogating Doppler beam and longitudinal motion of the ventricle was kept as small possible. The myocardial systolic wave (Sm) velocity, myocardial precontraction time (PCTm; from the onset of ECG QRS to the beginning of Sm), and myocardial contraction time (CTm; from the beginning to the end of Sm) were measured and the PCTm:CTm ratio was calculated. The diastolic indices were myocardial early (Em) and atrial contraction (Am) peak velocities, Em:Am ratio, and myocardial relaxation time (time interval between the end of Sm and the onset of Em) (fig 1).

\section{Reproducibility}

The reproducibility of EF and end systolic diameter measurements was tested with 20 randomly selected patients. The intraobserver regression coefficients were 0.93 for EF and 0.95 for end systolic diameter. The interobserver regression coefficients were 0.90 for EF and 0.92 for end systolic diameter. Low coefficients of variation were found (intraobserver 6\% for EF and $4 \%$ for end systolic diameter for operator 1 , and $6 \%$ for EF and $7 \%$ for end systolic diameter for operator 2; interobserver 5\% for EF and $4 \%$ for end systolic diameter). Our methods and reproducibility regarding TDI indices were previously

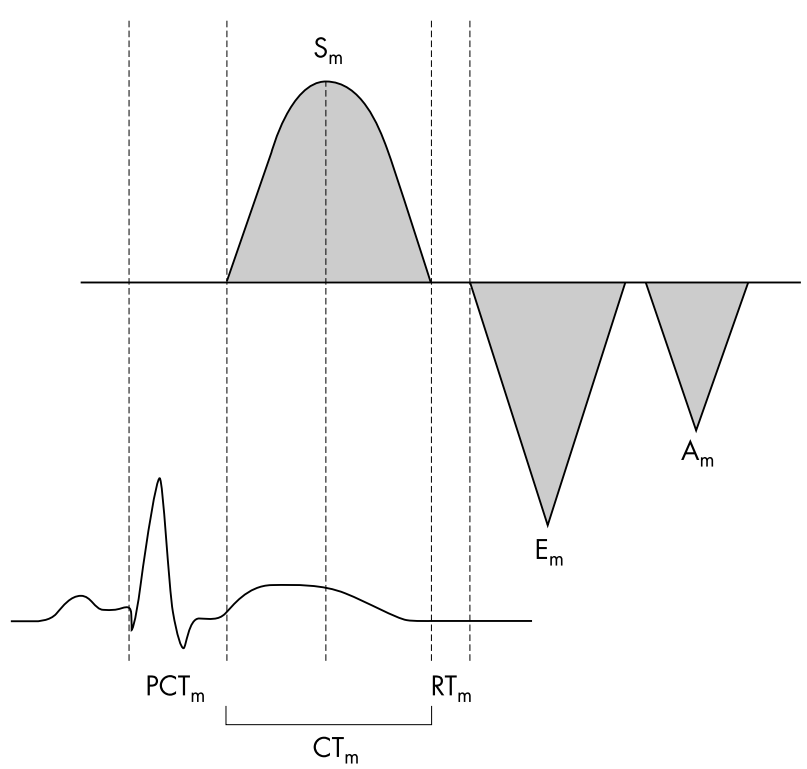

Figure 1 Schema of the tissue Doppler imaging pattern of the left ventricular mitral annulus. $A_{m}$, late diastolic wave; $C T_{m}$, myocardial contraction time; $\mathrm{E}_{\mathrm{m}}$, early diastolic wave; $\mathrm{PCT}_{\mathrm{m}}$, myocardial precontraction time; $\mathrm{RT}_{\mathrm{m}}$, myocardial relaxation time; $\mathrm{S}_{\mathrm{m}}$, myocardial systolic wave.

reported: the intraobserver and interobserver regression coefficients were $>0.85$ for all measurements in a population of 16 subjects. ${ }^{18}$

\section{Statistical analysis}

Data are expressed as mean (SD) or percentages. The differences between the groups were explored with the unpaired Student's $t$ test. Incidences in the groups were tested for significance with the $\chi^{2}$ test. Preoperative and postoperative data were compared by paired $t$ test. Linear correlations were analysed by Pearson's or Spearman's bivariate two tailed method. Multiple linear regression analysis was performed to identify the independent predictors of EF reduction $\geqslant 10 \%$. Sensitivity and specificity were calculated for systolic tissue Doppler indices and the receiver operating characteristic curves were constructed to obtain the best discriminant cut off values. A probability value of $\mathrm{p}<0.05$ was considered significant.

SPSS software (version 8.0, Chicago, Illinois, USA) was used for statistical analysis.

\section{RESULTS}

The echocardiographic examinations were done a mean (SD) of 4 (1) days preoperatively and 15 (3) days postoperatively. The surgical procedure was valve repair in 81 patients and valve replacement in three. No surgical complications were observed and the postoperative course was regular. A significant postoperative decrease in EF was noted (67 $(4.9) \% \vee 60(5.5) \%, p=0.0001)$. According to the reduction of EF after surgical correction, we identified 43 patients in group 1 (EF reduction $<10 \%$ ) and 41 in group 2 (EF reduction $>10 \%)$. EF decreased postoperatively in group 1 from $65(4) \%$ to $63(3) \%(\mathrm{p}=0.0001)$ and in group 2 from $68(5) \%$ to $57(5) \%(\mathrm{p}=0.0001)$ (fig 2$)$.

Moreover, a postoperative $\mathrm{EF}<50 \%$ was observed in seven $(8 \%)$ patients. There were no differences in baseline echocardiographic parameters, except for LV mass index, which was significantly higher in group 2 than in group 1 (table 2). 


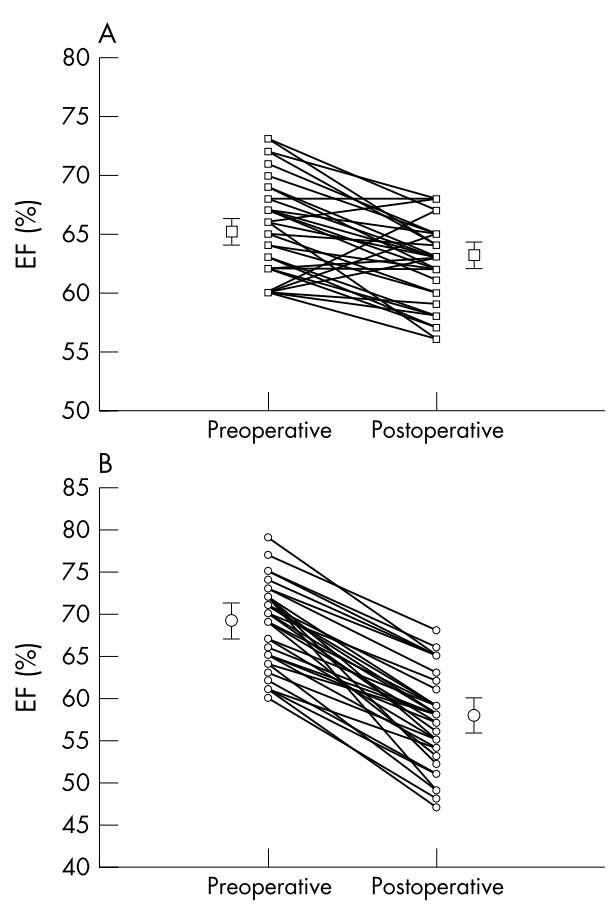

Figure 2 Plots showing the profile of ejection fraction (EF) change between baseline and after surgical correction in individual patients: (A) group 1; (B) group 2 .

\section{Tissue Doppler parameters}

In group 2, PCTm and CTm were significantly longer and Sm velocity of the mitral annulus was significantly lower than in group 1 (table 3 ).

All of these preoperative systolic parameters had a significant univariate correlation with postoperative EF: PCTm, $r=-0.53, \mathrm{p}=0.0001 ; \mathrm{CTm}, r=-0.61, \mathrm{p}=0.000 \mathrm{l}$; PCTm:CTm ratio, $r=-0.52, \mathrm{p}=0.0001$; and Sm velocity, $r=0.68, \mathrm{p}=0.005$. All the preoperative systolic TDI parameters had a significant correlation with EF changes (fig 3): PCTm, $r=0.58, \mathrm{p}=0.0001$; CTm, $r=0.51, \mathrm{p}=0.0001$; PCTm:CTm ratio, $r=0.56, \mathrm{p}=0.0001$; and Sm velocity, $r=-0.69, \mathrm{p}=0.0001$.

Significant univariate correlations were found between a postoperative EF reduction $\geqslant 10 \%$ and PCTm, CTm, PCTm:CTm ratio, and Sm velocity but no associations between postoperative $\mathrm{EF}$ reduction $\geqslant 10 \%$ and baseline echocardiographic parameters were observed (table 4). PCTm:CTm $\geqslant 40$ (sensitivity $82 \%$, specificity $60 \%$ ) and Sm velocity $\leqslant 10 \mathrm{~cm} / \mathrm{s}$ (sensitivity $90 \%$ and specificity $85 \%$ ) were the best discriminant cut off values of postoperative EF reduction $\geqslant 10 \%$ obtained by receiver operating characteristic curves.
Table 2 Comparison between patients with postoperative FE reduction $\leqslant 10 \%$ (group 1 ) and patients with postoperative FE reduction $>10 \%$ (group 2)

\begin{tabular}{llll}
\hline & $\begin{array}{l}\text { Group 1 } \\
(\mathbf{n}=\mathbf{4 3})\end{array}$ & $\begin{array}{l}\text { Group 2 } \\
(\mathbf{n}=\mathbf{4 1 )}\end{array}$ & p Value \\
\hline $\operatorname{EDD}(\mathrm{mm})$ & $57.5(8.7)$ & $58(6.2)$ & NS \\
$\operatorname{ESD}(\mathrm{mm})$ & $34.6(7.1)$ & $35.2(7.3)$ & NS \\
$\operatorname{EDV~}\left(\mathrm{ml} / \mathrm{m}^{2}\right)$ & $68.4(19.9)$ & $67.8(18.8)$ & NS \\
$\operatorname{ESV~}\left(\mathrm{ml} / \mathrm{m}^{2}\right)$ & $24.2(8.5)$ & $21.7(7.2)$ & NS \\
LVMI $\left(\mathrm{g} / \mathrm{m}^{2}\right)$ & $127.3(47.2)$ & $131(28.2)$ & 0.05 \\
EF $(\%)$ & $65.5(4.4)$ & $68.3(4.9)$ & NS \\
SPAP $(\mathrm{mm} \mathrm{Hg})$ & $31.5(10.5)$ & $31.4(8.9)$ & NS \\
\hline
\end{tabular}

Data are mean (SD)

NS, not significant.

Separate multiple linear regression analysis were performed to identify independent predictors of postoperative EF reductions $\geqslant 10 \%$. In the first model, with heart rate, age, PCTm:CTm, and Sm velocity as potential determinants, only Sm velocity was an independent predictor ( $\beta$ coefficient $-0.46, \mathrm{p}<0.001)$ of postoperative EF reduction $\geqslant 10 \%$ (cumulative $R^{2}=0.20$, standard error $(\mathrm{SE})=0.43 \mathrm{~cm} / \mathrm{s}$, $\mathrm{p}<0.001)$. In the second model, the interaction of PCTm:CTm $\geqslant 40$ and $S m$ velocity $\leqslant 10 \mathrm{~cm} / \mathrm{s}$ was independently associated with postoperative EF reduction $\geqslant 10 \%$ ( $\beta$ coefficient 0.57, $\mathrm{p}<0.0001$; cumulative $R^{2}=0.31$, $\mathrm{SE}=0.40, \mathrm{p}<0.0001$; sensitivity $78 \%$, specificity $95 \%$; table 5).

Finally, no significant differences between the groups were noted in the diastolic indices such as Em and Am peak velocities and Em:Am ratio (table 3 ).

\section{DISCUSSION}

The present study shows that in patients with MR and apparently normal LV function, long axis contraction of the left ventricle is preciously and noticeably altered and its assessment by TDI of the LV mitral annulus can predict the postoperative decrease of EF. TDI assesses myocardial function, whereas EF and LV internal dimensions reflect haemodynamic consequences of both MR volume overload and myocardial function. Thus, TDI can be used for the early detection of myocardial dysfunction and may be a simple and reliable indicator of early LV dysfunction in patients with chronic volume overload.

Global LV systolic function can be assessed by LV mitral annular velocity in the apical views, providing important insight in terms of amplitude, velocity, and timing in relation to the cardiac cycle. ${ }^{19}$ It has been shown that peak systolic velocity correlates well with LVEF. ${ }^{20} 21$ Other investigators have shown that $\mathrm{Sm}$ velocity, measured from the apical approach, correlated with peak positive $\mathrm{dP} / \mathrm{dt}$ and $\mathrm{EF}$ in patients with dilated cardiomyopathy. ${ }^{22}$ TDI not only defines and measures mitral annular movement but, because of its high temporal resolution, also provides a useful estimate of

\begin{tabular}{llll} 
Table 3 & TDI measurements: subgroups analysis & & \\
\hline & Group $\mathbf{1}(\mathbf{n}=\mathbf{4 3})$ & Group $\mathbf{2}(\mathbf{n}=\mathbf{4 1 )}$ & $\mathbf{p}$ Value \\
\hline PCTm $(\mathrm{ms})$ & $82(21.8)$ & $100.4(19)$ & 0.004 \\
CTm $(\mathrm{ms})$ & $215(2.3)$ & $222(3.1)$ & 0.01 \\
PCTm:CTm & $0.38(0.09)$ & $0.45(0.08)$ & 0.001 \\
Sm velocity $(\mathrm{cm} / \mathrm{s})$ & $13(1.3)$ & $10.4(1.1)$ & 0.0001 \\
Em peak velocity $(\mathrm{cm} / \mathrm{s})$ & $14.8(3.4)$ & $13.7(3)$ & $\mathrm{NS}$ \\
Am peak velocity $(\mathrm{cm} / \mathrm{s})$ & $13.5(3.8)$ & $12.1(4.2)$ & $\mathrm{NS}$ \\
Peak Em:Am & $1(0.2)$ & $1.3(0.6)$ & $\mathrm{NS}$ \\
RTm $(\mathrm{ms})$ & $70(2.3)$ & $72(1.5)$ & $\mathrm{NS}$ \\
\hline
\end{tabular}

Am, late diastolic wave; CTm, contraction time; Em, early diastolic wave; PCTm, myocardial precontraction time $\mathrm{RTm}$, relaxation time; $\mathrm{Sm}$, myocardial systolic wave. 


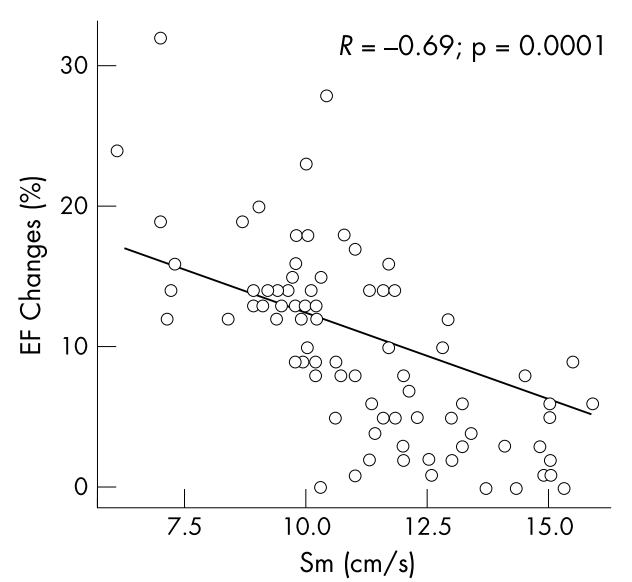

Figure 3 Correlation between EF changes and baseline myocardial systolic wave $(\mathrm{Sm})$ velocity.

myocardial (both systolic and diastolic) time intervals. ${ }^{23-25}$ PCTm is the myocardial systolic time corresponding to the isometric period before the onset of myocardial contraction, whereas CTm corresponds to the contraction period. The PCTm:CTm ratio, corresponding to the ratio of the LV preejection period to the LV ejection time obtained by standard Doppler assessment of the LV outflow tract, may be considered to be an index inversely correlated to myocardial contractility. ${ }^{26}$ TDI velocities are influenced by physiological factors and by the complexity of myocardial fibre architecture and orientation relative to long and short axis LV contraction and relaxation. ${ }^{27}$ The subendocardial fibres are aligned longitudinally and are connected with the mitral annulus; therefore, the measurement of myocardial velocities from the apical views with pulsed TDI reflects LV longitudinal shortening and relaxation. ${ }^{27} 28$

How to assess LV function in MR is not completely understood. Preoperative EF is the best predictor of long term mortality under conservative management and after surgery for congestive heart failure, as well as of postoperative residual LV function. ${ }^{136}$ Also, LV end systolic dimension is an alternative predictor of postoperative LV function. ${ }^{6}$ The cut off values for defining a high risk population are an EF of about $<60 \%$ and an end systolic diameter $>45 \mathrm{~mm} .{ }^{6}$ It is worth noting that increased LV diastolic inflow volume increases preload. During systole, the regurgitant flow towards the left atrium suggests a decreased impedance to ejection but end systolic wall stress is usually normal. With the development of LV dysfunction, EF may fall but, because of the reduced afterload, it can remain within normal limits, thus masking the presence of myocardial dysfunction.

TDI velocities may be more sensitive markers than EF for two reasons: firstly, because TDI indices are relatively preload independent and, secondly, because of the architecture and activation of myocardial fibres. ${ }^{21}$ In fact, long axis shortening (from longitudinal fibres) occurs before short axis shortening during the isovolumic contraction phase, whereas the ejection phase is due mainly to shortening of circumferential fibres in the short axis. Therefore, when subendocardial ischaemia occurs, impaired long axis shortening is evident before changes in the short axis because of the orientation of the myocardial fibres. ${ }^{29}$ It is worth noting that the TDI derived annular peak systolic velocity increases significantly at very low dose dobutamine ( $1 \mu \mathrm{g} / \mathrm{kg} / \mathrm{min}$ ) and no change of LVEF corresponds to the linear dose dependent increase of the velocity until $3 \mu \mathrm{g} / \mathrm{kg} / \mathrm{min}$. This supports the hypothesis that mitral annular velocity is more sensitive to EF as a marker of LV contractility. ${ }^{30}$
Table 4 Correlation between baseline TDI and conventional echocardiographic parameters with postoperative $\mathrm{EF}$ reduction $\geqslant 10 \%$

\begin{tabular}{lll}
\hline & $\begin{array}{l}\text { Correlation with postoperative } \\
\text { EF reduction } \geqslant 10 \%\end{array}$ & $\mathrm{p}$ Value \\
\hline PCTm & 0.43 & 0.0001 \\
CTm & 0.38 & 0.001 \\
PCTm:CTm & 0.43 & 0.0001 \\
Sm velocity & -0.45 & 0.0001 \\
ESD & 0.15 & $\mathrm{NS}$ \\
ESV & 0.16 & $\mathrm{NS}$ \\
EF & -0.26 & $\mathrm{NS}$ \\
\hline
\end{tabular}

In the present study, peak systolic velocities were relatively high. This is probably because preoperative EF was preserved in these patients. However, all systolic TDI parameters correlated well with postoperative EF, suggesting that subnormal values of TDI systolic indices should be considered to be abnormal in patients with MR.

Some limitations of the study have to be mentioned. Firstly, we chose as an end point a postoperative EF reduction $>10 \%$ instead of a postoperative EF $<50 \%$. The $10 \%$ cut off value was chosen assuming that EF decreases significantly after surgical correction by approximately $10 \%$, as reported by other authors. ${ }^{6}{ }^{15}$ We did not focus the study on the clinical postoperative significant reduction of EF $<50 \%$ because we usually recommend surgery when the EF is $>60 \%$, so minimising the chance of having several patients with postoperative EF $<50 \%$. However, our data showed a good linear correlation between baseline TDI systolic indices and postoperative EF. Secondly, we did not report postoperative TDI systolic indices because all patients who underwent mitral valve repair received a prosthetic annular ring. Other patients received a prosthetic valve, and their assessment would not have been easy or homogeneous for TDI application. Lastly, the postoperative echocardiographic examination was performed a mean of 15 days after surgery. The optimal time for assessment of postoperative EF is not clear but usually no differences are noted between early and late follow up values. ${ }^{6}$ However, it is questionable whether the fall in EF that we observed is reversible and whether TDI indices can predict recovery.

Our findings may have important clinical implications. The best outcome was observed in patients with an EF $>60 \%$ and an LV end systolic diameter $<45 \mathrm{~mm}$. Of interest, this disease stage provides the best opportunity for surgery even when no or minimal symptoms are detectable. ${ }^{6}$ In the present study, the baseline EF and LV internal dimensions were not reliable predictors of LV systolic function after surgical correction of MR, probably because of the narrow range of $\mathrm{EF}(>60 \%)$ and LV end systolic diameter $(<45 \mathrm{~mm})$ of our

Table 5 Results of multivariate analysis

\begin{tabular}{lll}
\hline $\begin{array}{l}\text { Determinants of postoperative EF } \\
\text { reduction } \geqslant 10 \%\end{array}$ & $\boldsymbol{\beta}$ Coefficients & $\boldsymbol{p}$ Value \\
\hline $\begin{array}{l}\text { First model } \\
\text { Sm velocity }\end{array}$ & -0.46 & 0.001 \\
PCTm:CTm & 0.26 & 0.063 \\
Heart rate & 0.16 & 0.87 \\
Age & 0.12 & 0.35 \\
Second model & & \\
PCTm:CTm and Sm velocity & 0.57 & 0.0001 \\
Heart rate & 0.10 & 0.33 \\
Age & 0.15 & 0.15 \\
\hline & & \\
\hline
\end{tabular}


population.. Therefore, TDI systolic indices should be used to identify patients with latent LV dysfunction with good sensitivity and specificity. In this view, TDI assessment may be useful to obtain evidence of subclinical myocardial dysfunction and thereby to improve significantly the timing of mitral valve surgery.

In conclusion, even if the best outcome after surgical correction is observed in patients with an EF $>60 \%$, the capability to predict postoperative LV function is imperfect and EF may be significantly reduced after surgical correction. TDI systolic indices can predict a significant reduction in postoperative EF in asymptomatic patients with severe MR and normal EF and therefore may be useful markers to improve the clinical management of these patients.

\section{Authors' affiliations}

E Agricola, M Oppizzi, A Margonato, Division of Non-Invasive Cardiology, San Raffaele Hospital, IRCCS, Milan, Italy

M Galderisi, Department of Clinical and Experimental Medicine, Federico II University of Naples, Naples, Italy

A F L Schinkel, Department of Cardiology, Thoraxcentre, Erasmus MC, Rotterdam, Netherlands

F Maisano, M De Bonis, O Alfieri, Division of Cardiac Surgery, San Raffaele Hospital, IRCCS, Milan, Italy

A Maseri, Vita e Salute University, San Raffaele, Milan, Italy

\section{REFERENCES}

1 Enriquez-Sarano M, Schaff HV, Orszulak TA, et al. Congestive heart failure after surgical correction of mitral regurgitation: a long-term study. Circulation 1995; $92: 2496-503$

2 Enriquez-Sarano M, Tajik AJ, Schaff HV, et al. Echocardiographic prediction of survival after surgical correction of organic mitral regurgitation. Circulation 1994:90:830-7.

3 Ling $\mathrm{H}$, Enriquez-Sarano M, Seward J, et al. Clinical outcome of mitral regurgitation due to flail leaflets. N Engl J Med 1996;335:1417-23.

4 Wisenbaugh T, Skudicky D, Sareli P. Prediction of outcome after valve replacement for rheumatic mitral regurgitation in the era of chordal preservation. Circulation 1994;89:191-7.

5 Crawford MH, Souchek J, Oprian CA, et al. Determinants of survival and left ventricular performance after mitral valve replacement. Department of Veterans Affairs cooperative study on valvular heart disease. Circulation 1990;81:1173-81.

6 Enriquez-Sarano M, Tajik A, Schaff H, et al. Echocardiographic prediction of left ventricular function after correction of mitral regurgitation: results and clinical implications. J Am Coll Cardiol 1994;24:1536-43.

7 Borow KM, Green LH, Mann T, et al. End-systolic volume as a predictor of postoperative left ventricular performance in volume overload from valvular regurgitation. Am J Med 1980;68:655-63.

8 Boucher CA, Bingham JB, Osbakken MD, et al. Early changes in left ventricular size and function after correction of left ventricular volume overload. Am J Cardiol 1981;47:991-4.

9 Carabello BA, Williams H, Gash AK, et al. Hemodynamic predictors of outcome in patients undergoing valve replacement. Circulation 1986;74:1309-16.
10 Pai RG, Bansal RC, Shah PM. Doppler-derived rate of left ventricular pressure rise: its correlation with the postoperative left ventricular function in mitral regurgitation. Circulation 1990;82:514-20.

11 Zile MR, Gaasch WH, Carroll JD, et al. Chronic mitral regurgitation: predictive value of preoperative echocardiographic indexes of left ventricular function and wall stress. J Am Coll Cardiol 1984;3:235-42.

12 Vinereanu D, lonescu AA, Fraser AG. Assessment of left ventricular long axis contraction can detect early myocardial dysfunction in asymptomatic patients with severe aortic regurgitation. Heart 2001;85:30-6.

13 Bach DS. Quantitative Doppler tissue imaging as a correlate of ventricular contractility. Int J Cardiac Imaging 1996; 12:191-5.

14 Pellerin D, Cohen L, Larrazet $F$, et al. Preejectional left ventricular wall motion in normal subjects using Doppler tissue imaging and correlation with ejection fraction. Am J Cardiol 1997;80:601-7.

15 Enriquez-Sarano M. Timing of mitral valve surgery. Heart 2002;87:79-85.

16 Mele D, Vandervoort P, Palacios I, et al. Proximal jet size by Doppler color flow mapping predicts severity of mitral regurgitation. Circulation 1995;91:746-54.

17 Devereux RB. Detection of left ventricular hypertrophy by M-mode echocardiography: anatomic validation, standardization and comparison to other methods. Hypertension 1987;9(suppl II):119-26.

18 Galderisi M, Caso P, Severino S, et al. Myocardial diastolic impairment caused by left ventricular hypertrophy involves basal septum more than other walls: analysis by pulsed Doppler tissue imaging. J Hypertens 1999; 17:685-93

19 Quiňones MA, Otto CM, Stoddard M, et al. Recommendations for quantification of Doppler echocardiography: a report from the Doppler quantification task force of the nomenclature and standards committee of the American Society of Echocardiography. J Am Soc Echocardiogr 2002; 15: 167-84

20 Gulati VK, Katz WE, Follansbee WP, et al. Mitral annular descent velocity by tissue Doppler echocardiography as an index of global left ventricular function. Am J Cardiol 1996;7:979-84.

21 Nagueh SF, Middleton KJ, Kopelen HA, et al. Doppler tissue imaging: a technique for evaluation of left ventricular relaxation and estimation of filling pressures. J Am Coll Cardiol 1997;30:1527-33.

22 Mishiro $\mathrm{Y}$, Oki T, Yamada $\mathrm{H}$, et al. Evaluation of left ventricular contraction abnormalities in patients with dilated cardiomyopathy with the use of pulsed tissue Doppler. J Am Soc Echocardiogr 1999;13:913-20.

23 Fukuda K, Oki T, Tabata T, et al. Regional left ventricular wall motion abnormalities in myocardial infarction and mitral annular descent velocities studied with pulsed tissue Doppler imaging. J Am Soc Echocardiogr 1998;11:841-8.

24 Vitale G, Galderisi M, Lupoli GA, et al. Left ventricular myocardial impairment in subclinical hypothyroidism assessed by a new ultrasound tool: pulsed tissue Doppler. J Clin Endocrinol Metab 2002;87:4350-5.

25 Caso P, Galderisi M, D’Andrea A, et al. Analysis by pulsed Doppler tissue imaging of ventricular interaction in long-distance competitive swimmers. Am J Cardiol 2002;90:193-7.

26 Weissler AM, Harris WS, Schoenfeld CD. Systolic time intervals in heart failure in man. Circulation 1968;37:149-52.

27 Waggoner AD, Bierig SM. Tissue Doppler imaging: a useful echocardiographic method for the cardiac sonographer to assess systolic and diastolic ventricular function. J Am Soc Echocardiogr 2001;14:1143-52.

28 Greenbaum RA, Ho SY, Gibson DG, et al. Left ventricular fibre architecture in man. Br Heart J 1981;45:248-63.

29 Jones CJH, Raposo L, Gibson DG. Functional importance of the long axis dynamics of the human left ventricle. Br Heart J 1990;63:215-20.

30 Gorcsan J, Deswal A, Mankad S, et al. Quantification of the myocardial response to low dose dobutamine using tissue Doppler echocardiographic measures of velocity and velocity gradient. Am J Cardiol 1998;81:615-23. 